\title{
Effects of treatment with bimatoprost $0.03 \%$ for 3 years in patients with normal-tension glaucoma
}

This article was published in the following Dove Press journal:

Clinical Ophthalmology

19 June 2014

Number of times this article has been viewed

Kenji Inoue'

Minako Shiokawa'

Takayuki Fujimoto'

Goji Tomita ${ }^{2}$

'Inouye Eye Hospital, Tokyo, Japan;

${ }^{2} 2$ nd Department of Ophthalmology,

Toho University School of Medicine,

Tokyo, Japan
Correspondence: Kenji Inoue Inouye Eye Hospital, 4-3 Kanda-Surugadai, Chiyoda-ku, Tokyo, Japan

Tel +8I 3329509 I I

Fax +8I 332950917

Email inoue-k@inouye-eye.or.jp
Purpose: To evaluate the effects of bimatoprost $0.03 \%$ single treatment for 3 years on intraocular pressure (IOP) and visual field performance.

Methods: We monitored the IOP of 62 patients with normal-tension glaucoma every 1-3 months. The Humphrey visual field test was performed every 6 months after treatment and the results obtained were compared to those before treatment. In addition, visual field performance was evaluated using trend and event analysis.

Results: The mean \pm standard deviation (SD) of IOP after treatment with bimatoprost for 3 years $(13.6 \pm 3.1 \mathrm{mmHg})$ was significantly lower than that before treatment $(16.8 \pm 2.4 \mathrm{mmHg}$, $P<0.0001)$. No change was observed in the mean deviation and pattern SD values of the Humphrey visual field before and 3 years after treatment. Worsening of visual field performance was observed in one patient (3.0\%) by using trend analysis and in four patients $(12.1 \%)$ by using event analysis. Treatment was discontinued in 17 patients $(27.4 \%)$ because of adverse reactions.

Conclusion: Bimatoprost $0.03 \%$ single treatment was effective in reducing the IOP at least during the 3 years of treatment, but visual field performance worsened by $3.0 \%-12.1 \%$ in patients with normal-tension glaucoma.

Keywords: IOP, visual field, trend analysis, event analysis

\section{Introduction}

Glaucoma is a disease with chronic progression of visual field defects because of the loss of retinal ganglion cells. The final goal of glaucoma treatment is to control the progression of visual field defects. Previous studies indicate that control of visual field defects is associated with a decrease in intraocular pressure (IOP). ${ }^{1,2}$ Epidemiological studies performed in Japan have indicated that the prevalence of glaucoma is $5 \%$ in individuals older than 40 years, and many patients have normal-tension glaucoma. ${ }^{3}$ Typically, a decrease in the IOP is achieved by administration of single-drug eye drops. Glaucoma eye drops prepared from different drugs decrease the IOP via different mechanisms. Typically, eye drops that have a high efficacy of decreasing the IOP, that do not exert systemic adverse reactions, and are required to be administered only once a day are selected; prostaglandin eye drops satisfy the above criteria, and thus they are the treatment of choice. Prostaglandin analogs include latanoprost, travoprost, tafluprost, and bimatoprost. A meta-analysis of the efficacy of prostaglandin analogs in decreasing the IOP showed that bimatoprost eye drops had the highest efficacy rate. ${ }^{4}$ There are many patients with normal-tension glaucoma in Japan; thus, many studies have reported the efficacy of bimatoprost eye drops in these patients. However, these previous studies had a short follow-up period of 1 month, ${ }^{5} 8$ weeks, ${ }^{6} 3$ months (12 weeks), ${ }^{7-9} 6$ months, ${ }^{10}$ and 52 weeks. ${ }^{11}$ Moreover, long-term administration is required to evaluate visual field preservation. To date, no studies have described 
visual field preservation in normal-tension glaucoma after administration of bimatoprost eye drops.

In the present study, the change in IOP, progression of visual field defects, and adverse reactions were prospectively investigated in normal-tension glaucoma patients who received bimatoprost eye drops for 3 years. Different methods were used to examine the progression of visual field defects.

\section{Subjects and methods}

The objective of the present study is the efficacy of the drug in decreasing IOP, maintenance efficacy of the visual field, and to investigate the safety of long-term administration of bimatoprost eye drops. Sixty-two eyes of 62 patients with normal-tension glaucoma ( 25 men and 37 women) who started receiving treatment with single agent bimatoprost 0.03\% eye drops from December 2009 to October 2010 at Inouye Eye Hospital were examined. The patients fulfilled the diagnostic criteria and did not correspond with the exclusion criteria. Follow-up examinations were performed for 3 years. The mean age of the patients was $57.4 \pm 12.6$ years (mean \pm standard deviation [SD]; range 25-81 years). The mean refractive value was $-4.6 \pm 4.1 \mathrm{D}(-20$ to $2.25 \mathrm{D})$. The criteria for the diagnosis of the condition as normaltension glaucoma were as follows: 1) IOP $<21 \mathrm{mmHg}$ when measured multiple times, diurnal variation included; 2) morphological characteristics such as thinning of the rim of the optic disk and defects in the retinal nerve fiber layer; 3) abnormal visual field detected by high reliability and reproducibility corresponding to criteria 1) and 2); 4) ruling out of other eye diseases or congenital abnormalities, which could be the cause of the abnormal visual field; and 5) normal open angle as shown by gonioscopy. The exclusion criteria were: 1) corrected eyesight $<0.5$; 2) surgery other than cataract surgery, laser surgery, and requirement of systemic or local treatment with steroids; and 3) abnormality observed on otolaryngological or neurosurgical examination; the patients were excluded if they met any one of these criteria. One eye per patient was included; if both eyes met the inclusion criteria and did not meet the exclusion criteria, the right eye was selected.

Bimatoprost $0.03 \%$ eye drops were administered once a day at night, and the IOP was measured every $1-3$ months by using a Goldmann applanation tonometer at approximately the same time of day. IOP was measured 9-20 hours after administration of bimatoprost. The visual field was examined every 6 months (Humphrey visual field program 30-2 SITA-Standard). Patients with false positive, false negative, or poor fixation of $20 \%$ or more were excluded from the analysis. Adverse reactions were investigated at every visit to the hospital. After informed consent was obtained from the patients, the purpose and contents of every examination were sufficiently explained.

IOP before administration and at 3, 6, 9, 12, 15, 18, 21, $24,27,30,33$, and 36 months after administration of bimatoprost, were compared using analysis of variance (ANOVA) and multiple comparison (Bonferroni/Dunn test). The mean deviation (MD) and pattern SD (PSD) before administration and at $6,12,18,24,30$, and 36 months after administration were compared using the Friedman test. The significance level was $P<0.05$. Evaluation of IOP was performed in 35 patients and analysis of visual field was performed in 33 patients who received bimatoprost eye drops. Moreover, the progression of visual field defects was judged using trend analysis $^{12}$ and event analysis. ${ }^{13}$

In trend analysis, a change in the MD value was analyzed by linear regression. ${ }^{12}$ From this, we calculated the unit of the change in the MD value per year $(\mathrm{dB} /$ year) which was a barometer expressed with statistical significance. In event analysis, the results obtained at the first two follow-up examinations were used as baseline values; the results obtained at subsequent examinations were compared to those at the baseline. ${ }^{13}$ If the value was above a certain level, then the condition of the patient was judged to have deteriorated. Glaucoma progression analysis was used to judge "tendency to progress". If the same three or more adjacent points of measurement showed a significant decrease two consecutive times, the patient was judged to show a "tendency to progress". In the present study, the "tendency to progress" became the point when progression of visual field defected.

\section{Results}

The mean IOP in patients before the administration of bimatoprost eye drops was $16.7 \pm 2.2 \mathrm{mmHg}$. The IOP was $21 \mathrm{mmHg}$ in three patients; $20 \mathrm{mmHg}$ in five patients; $19 \mathrm{mmHg}$ in four patients; $18 \mathrm{mmHg}$ in six patients; $17 \mathrm{mmHg}$ in 18 patients; $16 \mathrm{mmHg}$ in ten patients; $15 \mathrm{mmHg}$ in five patients; $14 \mathrm{mmHg}$ in eight patients; $13 \mathrm{mmHg}$ in one patient; $12 \mathrm{mmHg}$ in one patient; and $11 \mathrm{mmHg}$ in one patient.

Out of 62 cases, 27 cases discontinued; therefore, IOP analysis was conducted in the remaining 35 cases. The mean IOP was $12.5 \pm 2.1 \mathrm{mmHg}$ after 3 months of administration of bimatoprost; $13.2 \pm 2.1 \mathrm{mmHg}$ after 6 months; $13.2 \pm 2.3 \mathrm{mmHg}$ after 9 months; $12.6 \pm 2.2 \mathrm{mmHg}$ after 12 months; $13.4 \pm 2.0$ mmHg after 15 months; $13.2 \pm 2.2 \mathrm{mmHg}$ after 18 months; 


\section{$(\mathrm{mmHg})$}

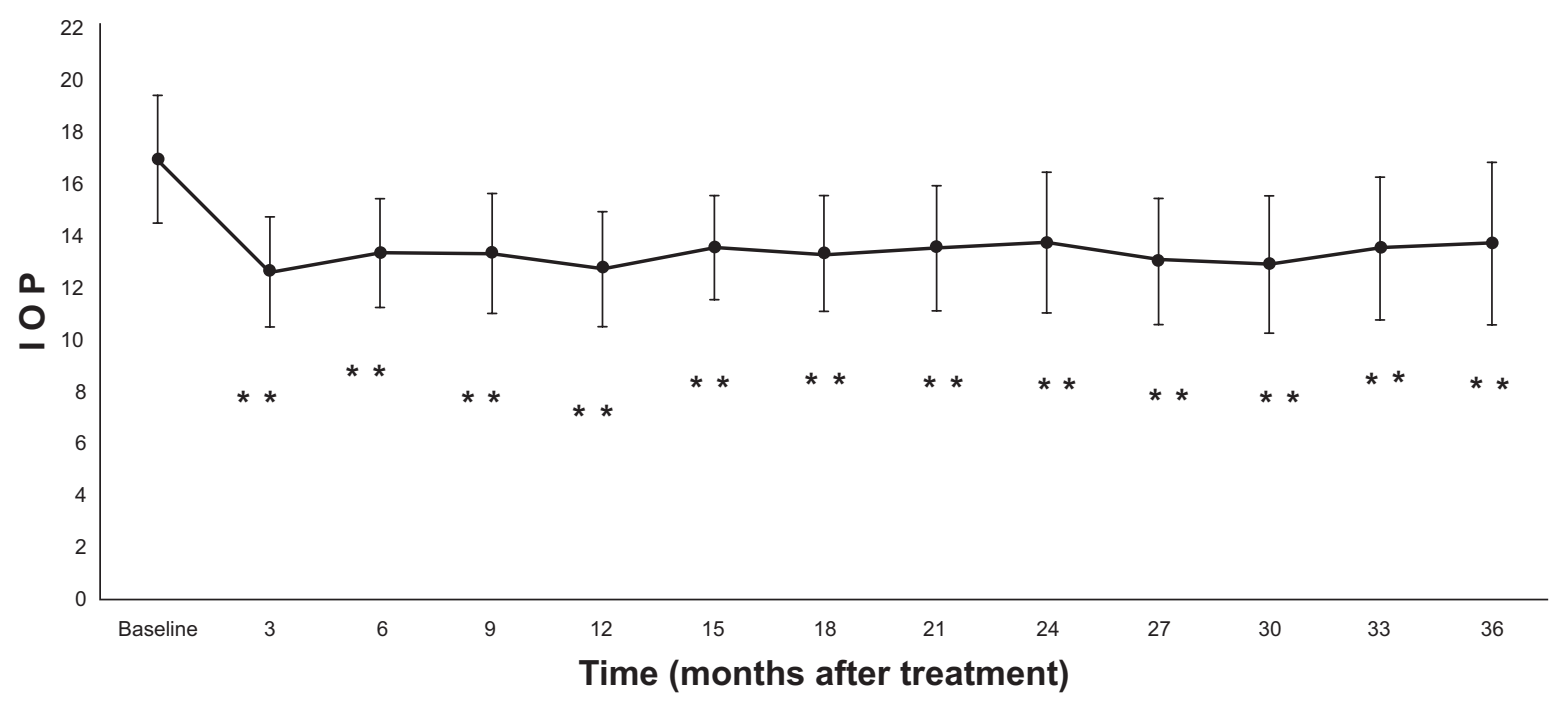

Figure I IOP at baseline and after treatment with bimatoprost.

Notes: Mean $\pm S D ; * * P<0.0001$, ANOVA.

Abbreviations: ANOVA, analysis of variance; IOP, intraocular pressure; SD, standard deviation.

$13.4 \pm 2.4 \mathrm{mmHg}$ after 21 months; $13.6 \pm 2.7 \mathrm{mmHg}$ after 24 months; $12.9 \pm 2.4 \mathrm{mmHg}$ after 27 months; $12.8 \pm 2.6 \mathrm{mmHg}$ after 30 months; $13.4 \pm 2.7 \mathrm{mmHg}$ after 33 months; and $13.6 \pm 3.1 \mathrm{mmHg}$ after 36 months (Figure 1). Compared to the values before administration, those after administration showed a significant decrease $(P<0.0001)$. There was no significant difference in the IOP decreasing rate at $3,6,9,12$, $15,18,21,24,27,30,33$, and 36 months after administration ( $P=0.0666$; Table 1$)$.

The MD value before administration was $-4.31 \pm 2.96 \mathrm{~dB}$ $(-10.23$ to $-0.06 \mathrm{~dB})$, and the PSD value was $6.36 \pm 3.76 \mathrm{~dB}$

Table I The rate of IOP decrease after treatment with bimatoprost

\begin{tabular}{ll}
\hline Time (months after treatment) & IOP decrease (\%) \\
\hline 3 & $24.9 \pm 9.7$ \\
6 & $20.9 \pm 10.7$ \\
9 & $20.8 \pm 12.8$ \\
12 & $24.3 \pm 11.3$ \\
15 & $19.4 \pm 8.8$ \\
18 & $20.9 \pm 12.1$ \\
21 & $19.8 \pm 10.3$ \\
24 & $18.6 \pm 10.3$ \\
27 & $22.7 \pm 10.6$ \\
30 & $23.6 \pm 11.8$ \\
33 & $19.7 \pm 12.3$ \\
36 & $19.4 \pm 11.7$ \\
$P$-value & 0.0666 \\
\hline
\end{tabular}

Notes: Mean \pm SD, ANOVA.

Abbreviations: ANOVA, analysis of variance; IOP, intraocular pressure; SD, standard deviation.
(2.02-15.05 dB). There was no significant difference in MD and PSD when comparing baseline with 6, 12, 18, 24, 30, and 36 months after administration (Table 2).

Of the 62 patients, 27 discontinued administration and two were excluded because poor fixation was more than $20 \%$ in the Humphrey visual field test and reliable examination reports could not be obtained more than five times. Trend analysis and event analysis were performed in the remaining 33 patients. Visual field defects were judged as "statistically significant" in one patient (3.0\%) in trend analysis and "tendency to progress" in four patients $(12.1 \%)$ in event analysis. No patients showed progression of visual field defects in both trend analysis and event analysis.

Treatment was discontinued in 27 patients (43.5\%). Adverse reactions occurred in 17 patients; the adverse

Table 2 MD and PSD at baseline, 6, 12, 18, 24, 30, and 36 months after treatment with bimatoprost

\begin{tabular}{lll}
\hline Time (months after treatment) & MD (dB) & PSD (dB) \\
\hline Baseline & $-4.31 \pm 2.96$ & $6.36 \pm 3.76$ \\
6 & $-3.91 \pm 3.36$ & $6.34 \pm 4.13$ \\
12 & $-3.86 \pm 3.65$ & $6.25 \pm 4.28$ \\
18 & $-4.02 \pm 3.72$ & $6.15 \pm 4.31$ \\
24 & $-3.94 \pm 3.93$ & $6.44 \pm 4.75$ \\
30 & $-3.68 \pm 3.38$ & $6.28 \pm 4.33$ \\
36 & $-3.22 \pm 3.56$ & $5.96 \pm 4.00$ \\
$P$-value & 0.0568 & $0.488 I$ \\
\hline
\end{tabular}

Notes: Mean \pm SD, Friedman test.

Abbreviations: MD, mean deviation; PSD, pattern standard deviation; SD, standard deviation. 
Table 3 Adverse reactions after treatment with bimatoprost

\begin{tabular}{lllll}
\hline Adverse reactions & \multicolumn{2}{l}{ Appearance period } & \\
\hline Conjunctival & I month & 6 months & 30 months & \\
hyperemia & 3 cases & I case & I case & \\
Deepening of upper & 4 months & 7 months & I 5 months & 30 months \\
eyelid sulcus & I case & 2 cases & I case & I case \\
Eyelid & 2 months & 3 months & I 4 months & \\
pigmentation & I case & I case & I case & \\
Lengthening & 3 months & & \\
of eyelashes & I case & & \\
Ophthalmalgia & 3 months & & \\
& I case & & \\
Itchiness & I 4 months & & \\
& I case & & \\
Blurriness & 4 months & \\
& I case & & \\
\end{tabular}

reactions included conjunctival hyperemia in five patients; deepening of the upper eyelid sulcus in five patients; eyelid pigmentation in three patients; lengthening of the eyelashes in one patient; ophthalmalgia in one patient; itchiness in one patient; and blurriness in one patient (Table 3). Other patients in whom treatment was discontinued included six patients in whom follow-ups were discontinued, three patients with progression of visual field defects, and one patient in whom additional eye drops were administered because of an insufficient decrease in the IOP.

\section{Discussion}

The rate of decrease in the IOP with bimatoprost reported previously in normal-tension glaucoma patients was $21.9 \%{ }^{5}$ after 1 month of administration, $15.5 \%{ }^{6}$ after 8 weeks of administration, $19.9 \%{ }^{7}$ after 12 weeks of administration, $16.0 \%^{8}$ after 3 months of administration, $17.5 \%-21.6 \%{ }^{9}$ and $23.0 \% \pm 10.7 \%{ }^{10}$ after 6 months of administration, and $28.1 \% \pm 9.4 \%{ }^{11}$ after 52 weeks of administration. Our results showed that the rate of decrease in the IOP after 3 years of administration was $19.4 \% \pm 11.7 \%$, which was thought to be similar to that reported previously. ${ }^{5-11}$

Adverse reactions associated with bimatoprost include conjunctival hyperemia, itching, irritation, stinging, foreign body sensation, dryness, eye pruritus, growth of eyelashes, iris hyperpigmentation, eyelid pigmentation, deepening of the upper eyelid sulcus, and superficial punctate epitheliopathy. ${ }^{6-11}$ The adverse reactions observed in our study were similar to those reported in previous studies. ${ }^{6-11}$ The frequency of discontinuation of bimatoprost because of the appearance of adverse reactions was higher in our study $(27.4 \%)$ than in previous studies $(3.0 \%, 5.3 \%, 8.1 \%$, and $16.7 \%)^{7,9-11}$ This finding may be because the duration of administration was longer ( 3 years) in our study than that in previous studies (3 months to 52 weeks) ${ }^{7,9-11}$ However, in the present study, the percentage of discontinued cases within 1 year of administration was $19.4 \%$, which is not significantly different to that found after 52 weeks of administration in previous studies. ${ }^{7,11}$

To date, the effect of long-term administration of bimatoprost eye drops on the visual field defect caused by normal-tension glaucoma patients has not yet been described. In this study, we observed no change in the MD and PSD values before and 12, 24, and 36 months after administration of bimatoprost. On the other hand, event analysis and trend analysis indicated a progression in visual field defects of $12.1 \%$ and $3.0 \%$, respectively. In previous studies, benzalkonium chloride (BAK)-free travoprost eye drops ${ }^{14}$ or tafluprost eye drops ${ }^{15}$ were administered to normal-tension glaucoma patients for 3 years. Progression in visual field defects was investigated by event analysis and trend analysis. In patients receiving BAK-free travoprost eye drops ${ }^{14}$ the results of event analysis and trend analysis were $13.9 \%$ and $2.8 \%$, and those in patients receiving tafluprost eye drops, ${ }^{15}$ were $10.3 \%$ and $13.8 \%$, respectively. In event analysis, the three drugs achieved similar results. Trend analysis showed that administration of bimatoprost eye drops may be more effective than administration of tafluprost eye drops. Moreover, its efficacy was almost the same as that for travoprost. In our study, the administration of bimatoprost was discontinued in three patients because of visual field defect progression during the 3-year follow-up period. IOP significantly decreased over this time but there were cases where visual field defects progressed. Only the decrease in IOP can be evaluated quantitatively, while defects in the control of progression of visual field cannot be evaluated quantitatively..$^{16}$ Even if IOP decreased sufficiently, there have been cases where visual field defects progressed in the Collaborative Normal-Tension Glaucoma study. ${ }^{1}$ It is thought that this is due to factors other than IOP.

The limitations for this present study are that it was not blinded, there was no control group, and there was no standard for discontinuing eye drops.

In conclusion, bimatoprost-only eye drops were administered to normal-tension glaucoma patients for 3 years. The IOP significantly decreased compared to baseline for 3 years. However, progression in visual field defects occurred in $3.3 \%-12.1 \%$ of the patients. The administration of bimatoprost was discontinued in $27.4 \%$ of the patients because of the appearance of adverse reactions. No patients in the present study experienced any systemic adverse reactions. Glaucoma 
treatment continues for a lifetime; therefore, more long-term efficacy studies need to be carried out.

\section{Disclosure}

The authors report no conflicts of interest in this work.

\section{References}

1. Collaborative Normal-Tension Glaucoma Study Group. Comparison of glaucomatous progression between untreated patients with normaltension glaucoma and patients with therapeutically reduced intraocular pressures. Am J Ophthalmol. 1998;126(4):487-497.

2. The AGIS Investigators. The Advanced Glaucoma Intervention Study (AGIS):7. The relationship between control of intraocular pressure and visual field deterioration. Am J Ophthalmol. 2000;130(4):429-440.

3. Iwase A, Suzuki Y, Araie M, et al; Tajimi Study Group, Japan Glaucoma Society. The prevalence of primary open-angle glaucoma in Japanese: the Tajimi Study. Ophthalmology. 2004;111(9):1641-1648.

4. van der Valk R, Webers CA, Schouten JS, Zeegers MP, Hendrikse F, Prins $\mathrm{MH}$. Intraocular pressure-lowering effects of all commonly used glaucoma drugs: a meta-analysis of randomized clinical trials. Ophthalmology. 2005;112(7):1177-1185.

5. Zeitz O, Matthiessen ET, Reuss J, et al. Effects of glaucoma drugs on ocular hemodynamics in normal tension glaucoma: a randomized trial comparing bimatoprost and latanoprost with dorzolamide [ISRCTN18873428]. BMC Ophthalmol. 2005;5:6.

6. Quaranta L, Pizzolante T, Riva I, Haidich AB, Konstans AG, Stewart WC. Twenty-four-hour intraocular pressure and blood pressure levels with bimatoprost versus latanoprost in patients with normal-tension glaucoma. Br J Ophthalmol. 2008;92(9):1227-1231.

7. Tsumura T, Yoshikawa K, Suzumura H, et al. Bimatoprost ophthalmic solution $0.03 \%$ lowered intraocular pressure of normal-tension glaucoma with minimal adverse events. Clin Ophthalmol. 2012;6:1547-1552.
8. Tanabe Y, Kanno M, Yamashita H. [Intraocular pressure-lowering effect of travoprost, tafluprost and bimatoprost in normal tension glaucoma]. Journal of the Eye. 2012;29(8):1131-1135. Japanese.

9. Dirks MS, Noecker RJ, Earl M, Roh S, Silverstein SM, Williams RD. A 3-month clinical trial comparing the IOP-lowering efficacy of bimatoprost and latanoprost in patients with normal-tension glaucoma. $A d v$ Ther. 2006;23(3):385-394.

10. Arai K, Inoue K, Shiokawa M, Masumoto M, Wakakura M, Tomita G. [Short-term effect of bimatoprost ophthalmic solution for normaltension glaucoma]. Japanese Journal of Clinical Ophthalmology. 2011; 65(7):1083-1088. Japanese.

11. Araie M, Kitazawa Y. [Long-term efficacy and safety of $0.03 \%$ bimatoprost ophthalmic solution in patients with open-angle glaucoma or ocular hypertension]. Journal of the Eye. 2011;28(8):1209-1215. Japanese.

12. McNaught AI, Crabb DP, Fitzke FW, Hitchinqs RA. Visual field progression: comparison of Humphrey Statpac 2 and pointwise linear regression analysis. Graefes Arch Clin Exp Ophthalmol. 1996;234(7): $411-418$.

13. Flammer J, Drace SM, Augustiny L, Funkhouser A. Quantification of glaucomatous visual field defects with automated perimetry. Invest Ophthalmol Vis Sci. 1985;26(2):176-181.

14. Inoue $\mathrm{K}$, Iwasa M, Wakakura M, Tomita G. Effects of BAK-free travoprost treatment for 3 years in patients with normal tension glaucoma. Clin Ophthalmol. 2012;6:1315-1319.

15. Inoue K, Tanaka A, Tomita G. Effects of tafluprost treatment for 3 years in patients with normal-tension glaucoma. Clin Ophthalmol. 2013;7: 1411-1416.

16. Ernest PJ, Schouten JS, Beckers HJ, Hendrikse F, Prins MH, Webers CA. An evidence-based review of prognostic factors for glaucomatous visual field progression. Ophthalmology. 2013;120(3):512-519.
Clinical Ophthalmology

\section{Publish your work in this journal}

Clinical Ophthalmology is an international, peer-reviewed journal covering all subspecialties within ophthalmology. Key topics include: Optometry; Visual science; Pharmacology and drug therapy in eye diseases; Basic Sciences; Primary and Secondary eye care; Patient Safety and Quality of Care Improvements. This journal is indexed on

Submit your manuscript here: http://www.dovepress.com/clinical-ophthalmology-journal

\section{Dovepress}

PubMed Central and CAS, and is the official journal of The Society of Clinical Ophthalmology (SCO). The manuscript management system is completely online and includes a very quick and fair peer-review system, which is all easy to use. Visit http://www.dovepress.com/ testimonials.php to read real quotes from published authors. 